\title{
Key Concerns About the Current State of Bladder Cancer
}

\author{
A Position Paper From the Bladder Cancer Think Tank, the Bladder Cancer \\ Advocacy Network, and the Society of Urologic Oncology
}

Yair Lotan, MD'; Ashish M. Kamat, MD²; Michael P. Porter, MD³; Victoria L. Robinson, MD ${ }^{4}$; Neal Shore, $M D^{5}$; Michael Jewett, MD ${ }^{6}$; Paul F. Schelhammer, MD ; Ralph deVere White, $M D^{8}$; Diane Quale ${ }^{9}$; Cheryl T. Lee, MD ${ }^{10}$, on behalf of the Bladder Cancer Think Tank, the Bladder Cancer Advocacy Network and the Society of Urologic Oncology

\begin{abstract}
Bladder cancer is the fifth most common cancer in the United States and, on a per capita basis, is the most expensive cancer from diagnosis to death. Unfortunately, National Cancer Institute funding for bladder cancer is quite low when compared with other common malignancies. Limited funding has stifled research opportunities for new and established investigators, ultimately encouraging them to redirect research efforts to other organ sites. Waning interest of scientists has further fueled the cycle of modest funding for bladder cancer. One important consequence of this has been a lack of scientific advancement in the field. Patient advocates have decidedly advanced research efforts in many cancer sites. Breast, prostate, pancreatic, and ovarian cancer advocates have organized highly successful campaigns to lobby the federal government and the medical community to devote increased attention and funding to understudied malignancies and to conduct relevant studies to better understand the therapy, diagnosis, and prevention of these diseases. Bladder cancer survivors have lacked a coordinated advocacy voice until recently. A concerted effort to align bladder cancer advocates, clinicians, and urologic organizations is essential to define the greatest needs in bladder cancer and to develop related solutions. This position paper represents a collaborative discussion to define the most concerning trends and greatest needs in the field of bladder cancer as outlined by the Bladder Cancer Think Tank, the Bladder Cancer Advocacy Network, and the Society of Urologic Oncology. Cancer 2009;115:4096-103. (c) 2009 American Cancer Society.
\end{abstract}

KEY WORDS: bladder cancer, concerns, funding, advocacy.

Bladder cancer remains a significant health condition in the United States, with an estimated 68,800 new cases and 14,100 deaths from the disease expected in 2008. ${ }^{1}$ The disease affects men more than women, and incidence increases with age. At this time, there are over half a million people in the

Corresponding author: Yair Lotan, MD, Department of Urology, University of Texas Southwestern Medical Center, 5323 Harry Hines Boulevard, Dallas, TX 75390-9110; Fax: (214) 648-8786; Yair.Lotan@UTSouthwestern.edu

${ }^{1}$ Department of Urology, University of Texas Southwestern Medical Center, Dallas, Texas; ${ }^{2}$ Department of Urology, The University of Texas M. D. Anderson Cancer Center, Houston, Texas; ${ }^{3}$ Department of Urology, University of Washington, Seattle, Washington; ${ }^{4}$ Department of Surgery, University of Chicago, Chicago, Illinois; ${ }^{5}$ Grand Strand Urology, Myrtle Beach, South Carolina; ${ }^{6}$ Department of Urology, University of Toronto, Toronto, Canada; ${ }^{7}$ Department of Urology, University of Virginia, Charlottesville, Virginia; ${ }^{8}$ Department of Urology, University of California at Davis, Davis, California; ${ }^{9}$ Bladder Cancer Advocacy Network, Bethesda, Maryland; ${ }^{10}$ Department of Urology, University of Michigan, Ann Arbor, Michigan

We thank Mark Schoenberg, Kevin R. Loughlin, Gary D. Steinberg, Seth P. Lerner, and Jessie Au for their intellectual input and assistance with reviewing this article.

Received: November 3, 2008; Revised: November 25, 2008; Accepted: December 3, 2008

Published online June 17, 2009 in Wiley InterScience (www.interscience.wiley.com)

DOI: $10.1002 / c n c r .24463$, www.interscience.wiley.com 
Table 1. 2007 Estimates of New US Cancer Cases, Deaths, Incidence Rates, and Prevalence Based on the Surveillance, Epidemiology, and End Results Cancer Registry

\begin{tabular}{|c|c|c|c|c|c|}
\hline $\begin{array}{l}\text { Cancer } \\
\text { Site }\end{array}$ & $\begin{array}{l}2007 \\
\text { Estimated } \\
\text { No. of New } \\
\text { Cases }\end{array}$ & $\begin{array}{l}2007 \\
\text { Estimated } \\
\text { No. of } \\
\text { Deaths }\end{array}$ & $\begin{array}{l}2000-2004 \\
\text { Estimated } \\
\text { Incidence } \\
\text { per } 100,000 \\
\text { Person-Years }\end{array}$ & $\begin{array}{l}2007 \\
\text { Estimated } \\
\text { Prevalence }\end{array}$ & $\begin{array}{l}\% 2007 \\
\text { Estimated } \\
\text { Death/ } \\
\text { Prevalence }\end{array}$ \\
\hline Prostate & 218,890 & 27,050 & 168 & $2,024,489$ & 1.34 \\
\hline Lung & 213,380 & 160,390 & 64.5 & 358,128 & 44.79 \\
\hline Breast & 180,510 & 40,910 & $127.8^{*}$ & $2,420,213$ & 1.69 \\
\hline Colorectal & 153,760 & 52,180 & 51.6 & $1,076,335$ & 4.85 \\
\hline Bladder & 67,160 & 13,750 & 21.1 & 511,790 & 2.69 \\
\hline Non-Hodgkin lymphoma & 63,190 & 18,660 & 19.3 & 381,129 & 4.90 \\
\hline Kidney & 51,190 & 12,890 & 12.8 & 240,266 & 5.36 \\
\hline Leukemia & 44,240 & 21,790 & 12.3 & 208,620 & 10.44 \\
\hline Uterus & 39,080 & 7400 & 12.3 & 568,407 & 1.30 \\
\hline Pancreas & 37,170 & 33,370 & 11.4 & 28,447 & 117.31 \\
\hline Ovary & 22,430 & 15,280 & 7.4 & 172,765 & 8.84 \\
\hline Melanoma & 19,900 & 10,790 & 5.6 & 690,021 & 1.56 \\
\hline
\end{tabular}

${ }^{\star}$ Among women only.

United States living with a diagnosis of bladder cancer (Table 1). ${ }^{2}$ Most patients ( 75\%) present with non-muscle-invasive disease and, although they typically have a long survival, suffer from a high rate of tumor recurrence. Management of this population is costly because of the extended surveillance and repeated use of endoscopic and intravesical therapies. Patients with muscle-invasive and metastatic disease have a much more precarious survival outcome and also contribute greatly to the cost of bladder cancer care because of the expense of radical cystectomy and systemic chemotherapy. As a result, bladder cancer is the most expensive cancer in the United States, accounting for almost 3.7 billion US dollars (2001 values) in direct costs. ${ }^{3}$

Given the high incidence and prevalence of bladder cancer in the United States and the substantial cost of managing the disease, a significant research effort with supportive funding must be undertaken to ensure scientific and clinical advances. Ideally, such research initiatives would be supported by national research funding agencies. Instead, bladder cancer remains woefully underfunded in comparison with other diseases of its magnitude. In addition, there are a diminishing number of basic and clinical scientists devoting attention to the development of novel therapies and models in bladder cancer, and ultimately scientific and clinical advancements in the field have been slow.

The lack of scientific progress in bladder cancer may result from several factors. Until very recently, there has not been a coordinated national advocacy initiative for bladder cancer patients. Such an effort cannot be underestimated, as cancer advocacy groups have had a tremendous influence over clinicians, the general population, media outlets, federal agencies, and legislators. Concerted efforts by committed advocates have led to increased disease awareness, funding, and research. The success of these groups requires active partnerships with relevant national organizations to ensure the pursuit of common goals. Consequently, it will be beneficial for the Bladder Cancer Advocacy Network (BCAN), the parent organization of the Bladder Cancer Think Tank, to partner with the Society of Urologic Oncology (SUO) and the American Urologic Association (AUA) to define and pursue such common goals to ensure progress in the treatment of bladder cancer.

\section{Concerning Trends}

\section{Lack of public awareness}

One of the distinct challenges facing the field of bladder cancer is the lack of public awareness of either the disease or its risk factors. In contrast, there has been a tremendous increase in public awareness and understanding of other common cancers over the past 25 years. Daily, the lay public is confronted with newspaper, Internet, and magazine articles as well as television news segments about 
breast cancer, prostate cancer, or colon cancer. Bladder cancer has rarely received this type of media attention, and as a result, there is little public awareness about the most basic facts regarding this disease. Not since the death of Senator and presidential candidate Hubert Humphrey in 1978 has there been a public face to bring the bladder cancer story to the media. Moreover, whereas there is substantial public discussion about the connection between smoking and lung cancer, most people are unaware of the association between smoking and bladder cancer. ${ }^{4,5}$ In fact, most people do not realize that blood in the urine is the most common sign of the disease.

This lack of knowledge and understanding of the risks and signs of bladder cancer often leads to misdiagnosis, late diagnosis, limited treatment options, and a worse prognosis. Recent studies have demonstrated less than optimal referral patterns for hematuria. ${ }^{6-8}$ Only $36 \%$ of primary care physicians routinely refer patients with microscopic hematuria to urologists, according to a survey of 270 primary care physicians including internists, family practitioners, and gynecologists. ${ }^{6}$ Similarly, a health plan database of 926 patients with hematuria found that the rate of urologic referrals was $28 \%$ for women and $47 \%$ for men. ${ }^{7}$ Delays in diagnosis are common and can lead to a worse prognosis as a result of a more advanced stage at diagnosis. ${ }^{9}$ Many speculate that these types of delays may contribute to a greater proportion of deaths in women with bladder cancer. ${ }^{10}$

The lack of disease awareness and the resulting absence of public discussion regarding bladder cancer has had negative implications for public funding for bladder cancer research and for progress in disease treatment and survival. Although there have been improvements in the surgical techniques for treating muscle-invasive bladder cancer, as well as chemotherapeutics for the treatment of advanced disease, survival from muscle-invasive or metastatic disease has not improved significantly in decades. Our current understanding of bladder cancer biology lags behind that of other common tumor types, such as prostate and colon. Although the current competitive funding climate has hampered scientific progress in many diseases, we believe bladder cancer has been disproportionately affected by prolonged underfunding and the failure of the cancer research community to recognize bladder cancer as a significant clinical problem.

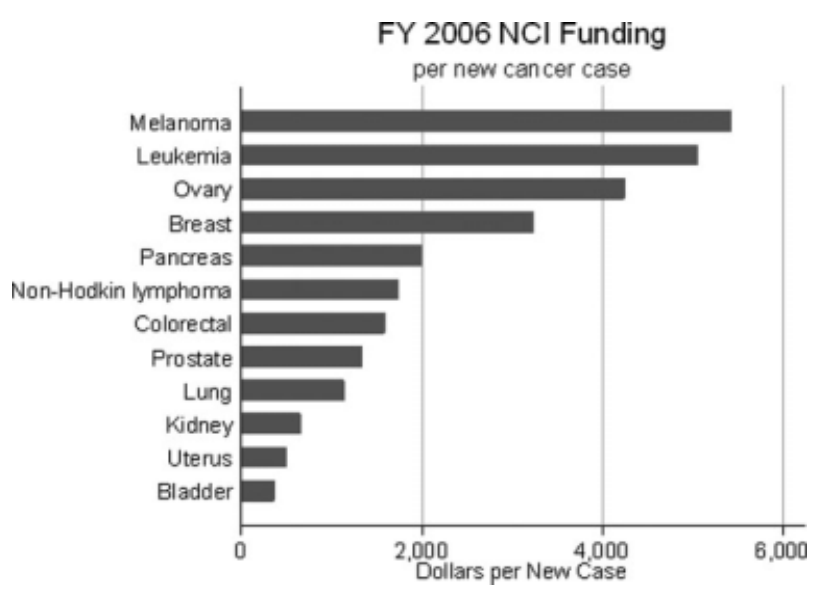

FIGURE 1. Fiscal year (FY) 2006 National Cancer Institute $(\mathrm{NCl})$ funding per new cancer case by cancer site is shown.

\section{Disproportionate funding}

Bladder cancer research continues to languish behind research performed in other disease sites. Although recent declines in funding are not unique to bladder cancer, prolonged trends in federal funding of bladder cancer research are disturbing (http://www.nih.gov/news/ fundingresearchareas.htm). Research dollars dedicated to bladder cancer have been decreasing since the year 2002, and currently, bladder cancer has the lowest "dollars per case" among common cancers (Fig. 1). These trends are disproportionate to the increasing cost of bladder cancer care in the United States and are a significant concern to the urologic community.

Determining the true cost of a disease process is challenging. Several studies have attempted to describe the costs of bladder cancer care in the United States. The seminal study that relied on population-based data was reported by Riley et al in $1995 .{ }^{11}$ By using tumor registry data from the Surveillance, Epidemiology, and End Results program (SEER) linked to Medicare claims, the cost of care was estimated for the 5 most common cancers in the United States. The lifetime per-person medical payment for bladder cancer was $\$ 57,629$ (1990 dollars). Prostate $(\$ 48,684)$, lung $(\$ 29,184)$, breast $(\$ 50,448)$, and colon/rectum $(\$ 51,865)$ lifetime costs were less.

More recently, Cooksley et al reported their findings using updated data from the SEER-linked Medicare claims. ${ }^{12}$ The incremental cost of care among patients with non-muscle-invasive bladder cancer was compared with those with muscle-invasive disease. The average 


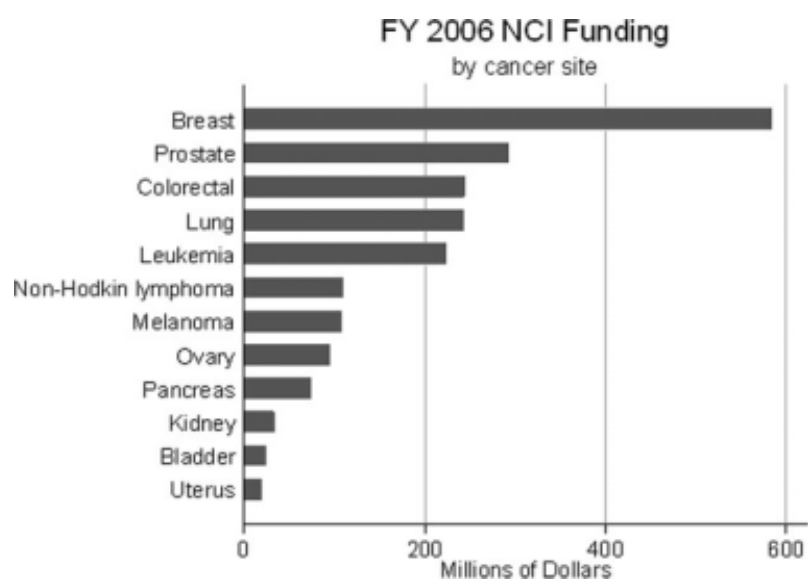

FIGURE 2. Fiscal year (FY) 2006 National Cancer Institute ( $\mathrm{NCl}$ ) funding by cancer site is shown.

annual cost of care was $\$ 36,000$ higher among those with muscle-invasive tumors compared with those with nonmuscle-invasive lesions ( $\$ 58,075$ vs $\$ 22,088,2006$ dollars). The authors concluded that the societal cost associated with bladder cancer could be reduced through the identification and treatment of early stage tumors before progression to muscle invasion.

In view of the high incidence and prevalence of bladder cancer in the United States, and the significant healthcare resources required to treat the disease, it is logical to expect that funding bladder cancer research would be a priority of national research funding agencies such as the National Institutes of Health (NIH) and the National Cancer Institute (NCI). Examination of the data, however, suggests otherwise. Figure 2 shows the fiscal year (FY) 2006 NCI budget for 12 of the most common cancers in the United States (most recent data publicly available, NCI statistics). Bladder cancer received $\$ 24.4$ million (M), a figure well below the 4 most common tumors, each of which received over $\$ 200 \mathrm{M}$ each. This figure is also well below most other common cancers. When considering dollars funded per incident case, bladder cancer receives the least funding of major cancers (Fig. 1). Likewise, when examining dollars funded per cancer-specific death, bladder cancer continues to be grossly underfunded (Fig. 3). The situation is further illustrated by the very small number of currently funded NIH research awards in bladder cancer as compared with the 6 most common cancers in the United States (Table 2). According to the NIH CRISP (Computerized

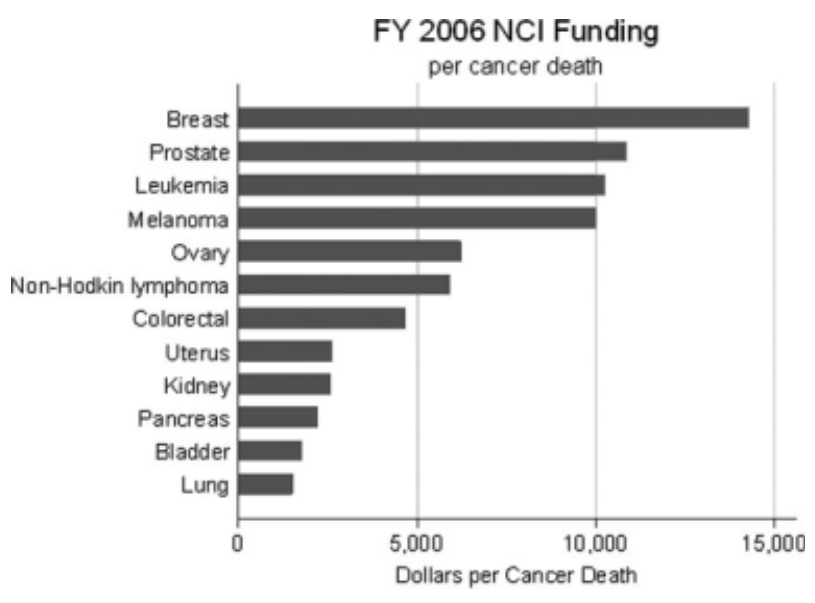

FIGURE 3. Fiscal year (FY) 2006 National Cancer Institute $(\mathrm{NCl})$ funding per site-specific cancer death is shown.

Table 2. FY2008 NIH-Funded Grants, Based on CRISP Data Base Search

\begin{tabular}{|c|c|c|}
\hline $\begin{array}{l}\text { Grant Title } \\
\text { Search Term }\end{array}$ & $\begin{array}{l}\text { Funded } \\
\text { R01 }\end{array}$ & $\begin{array}{l}\text { All Funded } \\
\text { NIH Grants }\end{array}$ \\
\hline Prostate cancer & 226 & 410 \\
\hline Lung cancer & 90 & 171 \\
\hline Breast cancer & 319 & 590 \\
\hline Colon cancer, rectal cancer & 139 & 256 \\
\hline Bladder cancer & 16 & 28 \\
\hline Lymphoma & 59 & 129 \\
\hline
\end{tabular}

FY indicates fiscal year; NIH, National Institutes of Health; CRISP, Computerized Retrieval of Information on Scientific Projects.

Retrieval of Information on Scientific Projects) database, only $16 \mathrm{R} 01$ grants and $28 \mathrm{NIH}$ grants containing the phrase "bladder cancer" in the title received funding in FY2008.

Certainly, the current funding environment in biomedical sciences is highly competitive, with the lowest funding rate in history. Flat funding over the last 5 years, combined with rising inflation and cost of biomedical research has led to many promising young scientists choosing to pursue alternative careers or science careers outside of academia. Real purchasing power for basic research suffered at least a net negative 13\% between 2003 and 2007. ${ }^{13}$ The proposed NIH biomedical research budget for 2009 amounts to a $0 \%$ increase over 2008. Despite these shortfalls in support, the incidence, prevalence, and cost of bladder cancer treatment demand more equitable funding from federal sources and large foundations. The few bladder-focused opportunities offered through the NIH are clinically oriented, with the 
exception of a single dedicated basic science R01 mechanism (Basic Research in the Bladder and Lower Urinary Tract). Aside from the NIH, no congressional funding dedicated to bladder cancer research has been earmarked through the Department of Defense. Similarly, the American Cancer Society (ACS) has funded very little work dedicated to bladder cancer.

Several factors may account for the low funding priority of bladder cancer research. One issue, as noted above, relates to the lack of public and scientific awareness of the prevalence of bladder cancer and the cost of managing the disease. Funding bladder cancer research may also be a low priority because of a historical lack of coordinated advocacy by individual patients and the urologic community. As a field, a sense of complacency has developed regarding research initiatives and community education efforts. Also noteworthy are the profound changes in body function and image that may occur after bladder cancer treatment, leaving bladder cancer survivors reluctant to speak publicly about their disease. For all of these reasons, it is imperative that urologists, together with patients and families, be intimately involved in future advocacy efforts if progress in the prevention, detection, and treatment of bladder cancer is to be realized.

\section{Declining basic science research}

Historically, bladder cancer research has primarily been clinical in nature, generating a wealth of treatmentbased and translational data. Tissue based studies have led to fundamental advancements in our understanding of urothelial carcinoma (UC) subtypes and of the diagnostic and prognostic implications of novel biomarker panels. Ultimately, gene expression arrays, genetic analysis, and immunohistochemistry studies have shown that lowgrade papillary and high-grade invasive disease are distinct at the molecular level. ${ }^{14}$ This evidence is consistent with differences in clinical behavior and histologic appearance long observed by urologists, pathologists, and oncologists.

Despite advances in the molecular characterization of urothelial tumors, there are relatively few detailed mechanistic studies investigating chromosomal regions and related function in UC. A lack of relevant models has hampered progress. Most of the available UC-derived cell lines were created in the 1970s, and animal models have relied on $\operatorname{dog}$ and rodent carcinogen models with acknowledged caveats. ${ }^{15}$ The uroplakin II transgenic mouse and normal human urothelium cultures are powerful tools, but are greatly underused in testing novel therapeutic concepts. Even the NCI-60 panel of cancer cell lines, often used in experiments to represent the most common tumor types, does not include bladder cell lines.

An important consideration in the lack of progress in basic research is the decline in young investigators entering the field. Bladder cancer suffers not only from a lack of awareness among the general public, but also among the scientific community, and thus few basic scientists recognize bladder cancer as a major clinical problem. Many scientists are unaware of the worldwide frequency of the disease, its high cost of therapeutic intervention, and the significant quality of life issues related to treatment. The limited number of investigators working in the bladder cancer field has resulted in a dearth of pivotal studies and a disproportionately low number of manuscripts in high-profile journals and presentations at conferences, further limiting exposure to both junior and senior scientists.

At the same time, cancer biologists have trended away from disease-specific questions toward more general biological questions that might apply to multiple tumors. Nevertheless, it is clear that a given tumor type may serve as a model for studying a favorite molecule, pathway, or process. For example, an interest in nuclear receptors may lead to investigation of the estrogen receptor in breast cancer or androgen receptor in prostate cancer. The bladder cancer model has many advantages. The accessibility of the organ for diagnostic procedures and treatment provide ready access to tissues necessary for translational studies and facilitates the study of novel drugs or drug delivery. Still, young scientists have not been readily attracted to the field.

The lack of senior basic scientists studying bladder cancer is yet another contributing factor to the failure of young scientists to pursue research in bladder cancer. New investigators often build careers on topics related to their training. Junior cancer biologists have likely trained in a well-funded area, such as breast or prostate cancer, angiogenesis, or tumor immunology. Without successful, wellfunded established investigators to recruit and train young scientists, there will continue to be few cancer biologists focused on bladder cancer. Likewise, if established scientists from a variety of research sectors do not support and encourage junior scientists to expand existing and related 
work into the bladder cancer research community, there will continue to be a shortage of novel scientific applications in our field.

At a time when federal funding is limited, an increasing number of basic science and clinical investigators have attempted to partner with industry to further scientific advancements. However, for many pharmaceutical companies, bladder cancer has a low prioritization in their corporate targets for disease-specific drug development. Thus, not only are young investigators facing decreasing returns on applications filed to the NIH, they also battle a perception among companies in industry that bladder cancer is "not financially viable." This perception is inconsistent, considering the \$2.9 billion spent in the United States last year to treat patients with bladder cancer. ${ }^{16}$

The climate, as it exists, translates into a vicious cycle-the lack of perceived benefit from a career in bladder cancer research deters young minds from entering the field, which in turn leads to fewer advances in bladder cancer therapy and fuels the perception that research in bladder cancer is a "futile cause." As such, it is not surprising that little progress has been made in the treatment of non-muscle-invasive bladder cancer since the introduction of Bacillus Calmette-Guerin in the $1970 s,{ }^{17}$ and in the treatment of advanced bladder cancer since methotrexate, vinblastine, doxorubicin, and cisplatin chemotherapy was first used in the 1980s. ${ }^{18}$

\section{Suggested Actions}

At this time, it is clear that the efforts of individual researchers have not been sufficient to spark a change in national policies or public awareness. The solution can be broken down into 2 simple needs: awareness and funding. Both needs require coordinated actions that will involve medical and scientific leadership, patient advocacy, and support from organizations such as the AUA and the SUO.

Until recently, and in contrast to most cancers, there was no patient advocacy organization dedicated to bladder cancer. Patient advocacy organizations have played critical roles in changing public perceptions of malignancies by increasing cancer-specific awareness and education and demanding improvements in available treatments and patient outcomes. Breast cancer provides a prime example. Since its inception in 1983, The Susan G. Komen
Foundation, along with its corporate partners, has provided more than $\$ 1$ billion for breast cancer research, education, screening, and treatment. At the same time, the NCI's funding for breast cancer has increased from $\$ 348$ million in 1998 to $\$ 560$ million in 2005 in response to the initiatives and pressures developed by this group's educational and outreach activities.

Advances in awareness of prostate cancer and improved options for treatment can be directly linked to the efforts of several advocacy organizations. In particular, the Prostate Cancer Foundation, founded in 1993, has raised more than $\$ 260$ million for prostate cancer research, and its advocacy efforts have resulted in a 20fold increase in government funding for prostate cancer. Awareness campaigns for prostate and breast cancer have also been aided by cancer-surviving celebrities and philanthropists who create popular platforms for advocacy and fundraising. NCI research budgets for these cancers and those represented by well-organized patient advocacy groups have increased rapidly. ${ }^{19}$

BCAN was launched in May 2005 as the first national patient advocacy organization dedicated to improving bladder cancer education and public awareness, and increasing research related to the prevention, diagnosis, and treatment of the disease. BCAN has already received the support of $>30$ prominent bladder cancer specialists in the United States who support its mission through service on its Scientific Advisory Board. The dedication and active participation of BCAN's founders and supporters will undoubtedly increase public awareness of bladder cancer and cement strategic planning to raise funds for research efforts.

Not only is a strong advocacy voice needed for bladder cancer, but a commitment to the formation of clinical and translational research consortia is necessary. As the advocacy groups raise awareness and stimulate the influx of funding, researchers in bladder cancer must develop and complete pertinent studies that will improve the management of the disease. The collaboration of existing research groups with overlapping scientific interests may be the most efficient approach to achieve this goal. A partnership between the Bladder Cancer "Think Tank" and the Bladder Cancer SPORE at the MD Anderson Cancer Center might be a natural collaboration, because a cooperative relationship could advance the objectives of both groups. It is certainly possible that the formation of consortia 
could provide the bladder cancer research community with bargaining power to better negotiate funding with federal agencies and the pharmaceutical industry.

Although advocacy groups and urologists have a role in encouraging research in bladder cancer, the role of national organizations such as the AUA, SUO, American Association of Cancer Research (AACR), and ACS cannot be underestimated. These organizations have the advantage of established funds to support research and diseasespecific fellowships. The AACR, for example, has the ability to prioritize education and funding for underserved areas of cancer research, such as bladder cancer, particularly for basic scientists. Such efforts may take the form of focused sessions at the AACR annual meeting, special conferences and workshops, devoted supplements of its journal affiliates, and the creation of funding mechanisms soliciting novel projects related to bladder cancer and the translation of findings from other organ-sites into bladder cancer models. Similar efforts are feasible within the SUO and the AUA. Both of these organizations can leverage bladder cancer-specific research awards and/or fellowships to direct research expertise into priority areas in the disease. The AUA, AACR, and ACS also have the advantage of well-established political action committees that can be effective in lobbying and educating the federal government about the importance of the disease, potentially impacting the priorities of the NCI.

Ultimately, academic urology departments must also make a committed effort to expand research in bladder cancer. Historically, clinician-scientists and basic scientist faculty of urology departments have been the driving force behind discoveries in urologic malignancies. The changing healthcare climate has made it more difficult for clinical faculty to allocate time and effort to research, potentially straining collaborations with basic scientists. However, it is important to maintain these relationships. As a result, several urology departments have recruited basic scientists as primary or secondary faculty members. Such initiatives can be challenging, as basic scientists are generally attracted to academic departments that offer an environment including colleagues with related interests, access to graduate students, core facilities and equipment, and opportunities for collaborations. Although clinical departments offer advantages regarding translational projects with direct clinical relevance, basic scientists may perceive involvement in a clinical department as a disadvantage, because the priorities of a clinical department may not coincide with the needs of a basic science laboratory. Still, these efforts have been highly successful for other disease sites in urology, such as prostate cancer.

\section{Conclusions}

Disparities in the financial and societal burden of a disease and its associated $\mathrm{NIH}$ funding for research are a significant point of concern for our legislators in Washington. They must be educated and informed to prompt action through legislative mandates. It is through these mandates and directives that budgeting and institutional $(\mathrm{NIH} /$ $\mathrm{NCI}$ ) attention is realized. Currently, bladder cancer presents an obvious inequity between public health, societal burden, and research funding. Public media attention is limited, and scientists have little incentive to commit to the field. Raising awareness among the general public and scientific community is essential to ensure that bladder cancer is recognized as an important healthcare issue in the United States. The correction of inequities in bladder cancer will require coordinated efforts between bladder cancer advocacy groups, national urologic and oncologic organizations, and legislators. Such cooperation will ultimately ensure improvements in the diagnosis, prevention, and treatment of bladder cancer.

\section{Conflict of Interest Disclosures}

The authors made no disclosures.

\section{References}

1. Jemal A, Siegel R, Ward E, et al. Cancer statistics, 2008. CA Cancer J Clin. 2008;58:71-96.

2. Ries LAG, Melbert D, Krapcho M, et al, eds. SEER Cancer Statistics Review, 1975-2004. Bethesda, MD: National Cancer Institute; 2007

3. Botteman MF, Pashos CL, Redaelli A, Laskin B, Hauser R. The health economics of bladder cancer: a comprehensive review of the published literature. Pharmacoeconomics. 2003; 21:1315-1330.

4. Zeegers MP, Tan FE, Dorant E, van Den Brandt PA. The impact of characteristics of cigarette smoking on urinary tract cancer risk: a meta-analysis of epidemiologic studies. Cancer. 2000;89:630-639.

5. Samanic C, Kogevinas M, Dosemeci M, et al. Smoking and bladder cancer in Spain: effects of tobacco type, timing, environmental tobacco smoke, and gender. Cancer Epidemiol Biomarkers Prev. 2006;15:1348-1354. 
6. Nieder AM, Lotan Y, Nuss GR, et al. Are patients with hematuria appropriately referred to Urology? A multi-institutional questionnaire based survey. Urol Uncol. In press.

7. Johnson EK, Daignault S, Zhang Y, Lee CT. Patterns of hematuria referral to urologists: does a gender disparity exist? Urology. 2008;72:498-502; discussion 502-503.

8. Singh R, Saleemi A, Walsh K, Popert R, O’Brien T. Near misses in bladder cancer-an airline safety approach to urology. Ann R Coll Surg Engl. 2003;85:378-381.

9. Wallace DM, Raghavan D, Kelly KA, et al. Neo-adjuvant (pre-emptive) cisplatin therapy in invasive transitional cell carcinoma of the bladder. Br J Urol. 1991;67:608615.

10. Jemal A, Siegel R, Ward E, Murray T, Xu J, Thun MJ. Cancer statistics, 2007. CA Cancer J Clin. 2007;57: 43-66.

11. Riley GF, Potosky AL, Lubitz JD, Kessler LG. Medicare payments from diagnosis to death for elderly cancer patients by stage at diagnosis. Med Care. 1995;33:828-841.

12. Cooksley CD, Avritscher EB, Grossman HB, et al. Clinical model of cost of bladder cancer in the elderly. Urology. 2008;71:519-525.
13. A broken pipeline? Flat funding of the NIH puts a generation of science at risk. Available at: http://www.brokenpipeline. org/ Accessed October 2008.

14. Wu XR. Urothelial tumorigenesis: a tale of divergent pathways. Nat Rev Cancer. 2005;5:713-725.

15. Crallan RA, Georgopoulos NT, Southgate J. Experimental models of human bladder carcinogenesis. Carcinogenesis. 2006;27:374-381.

16. National Cancer Institute. Cancer trends progress report 2007 update. Available at: http://progressreport.cancer.gov/ Accessed October 2008.

17. Morales A, Eidinger D, Bruce AW. Intracavitary Bacillus Calmette-Guerin in the treatment of superficial bladder tumors. 1976. J Urol. 2002;167(2 pt 2):891-893; discussion 893-895.

18. Sternberg CN, Yagoda A, Scher HI, et al. Preliminary results of M-VAC (methotrexate, vinblastine, doxorubicin and cisplatin) for transitional cell carcinoma of the urothelium. J Urol. 1985;133:403-407.

19. Brower V. The squeaky wheel gets the grease. Research funding is not necessarily allocated to those who need it most. EMBO Rep. 2005;6:1014-1017. 